\title{
Effect of Mycoplasma pulmonis on in-vivo fertilization in the mouse
}

\author{
Christine E. Swenson* \\ The Population Council, 1230 York Avenue, New York, New York 10021, U.S.A.
}

\begin{abstract}
Summary. When fresh, epididymal mouse spermatozoa were incubated with viable Mycoplasma pulmonis, the mycoplasma adhered to the heads and tails of spermatozoa. Spermatozoa that had been preincubated with $M$. pulmonis in phosphate-buffered saline (PBS) and spermatozoa incubated in PBS alone were inseminated into the uterine horns of mice induced to superovulate. The mycoplasma treatment resulted in a reduced rate of fertilization and a decrease in the number of spermatozoa associated with eggs recovered from the oviduct at 5-18 h after ovulation. The percentage of spermatozoa recovered from the oviduct with adherent mycoplasmas, as determined by fluorescence microscopy, was lower than that seen in the uterus. Mycoplasma treatment of spermatozoa inseminated directly into the ovarian bursa did not result in a reduced fertilization rate. The results suggest that $M$. pulmonis adversely affects sperm transport through the female reproductive tract in the mouse.
\end{abstract}

\section{Introduction}

For over a decade, the human genital mycoplasmas, Mycoplasma hominis and Ureaplasma urealyticum, have been suspected of causing a variety of reproductive disorders and infertility in man. Much of the evidence for this association comes from studies that have shown mycoplasmas to be more common in the lower genital tract of infertile couples than in fertile controls (Gnarpe \& Friberg, 1972, 1973a; O'Leary \& Frick, 1975). Mycoplasmas have been isolated from the human endometrium at a significantly higher rate from patients with a history of reproductive failure than from normal controls (Stray-Pedersen, Eng \& Reikvam, 1978; Koren \& Spigland, 1978). In addition, these organisms have been isolated during laparoscopy from the Fallopian tubes, pelvic fluid and tubo-ovarian abscesses of patients with salpingitis (Henry-Suchet \& Loffredo, 1980) and acute pelvic inflammatory disease (Mardh \& Westrom, 1970). How mycoplasmas reach these normally sterile sites and the mechanism(s) of their effect on fertility are not clearly understood.

Reproductive failure in rodents as a consequence of experimental intravenous or intraperitoneal inoculation with murine mycoplasmas has been demonstrated (Cole, Ward \& Golightly-Rowland, 1973; Taylor-Robinson, Rassner, Furr, Humber \& Barnes, 1975; Gabridge \& Cohen, 1976; Naot, Sharf \& Klein, 1978). The effect of mycoplasma on mouse fertilization and preimplantation development in vitro was examined by Fraser \& Taylor-Robinson (1977): when mouse spermatozoa were preincubated with $M$. pulmonis, fertilization occurred less

\footnotetext{
* Present address: Department of Laboratory Medicine, 1591 Health Sciences West, University of California, San Francisco, California 94143 , U.S.A.
} 
consistently than when untreated spermatozoa were used. There was also a significant reduction in development to the blastocyst stage.

The present study with mice was designed to examine the effect of mycoplasma on sperm function and fertilization in vivo, as well as the possibility that spermatozoa act as a vehicle to transport these organisms into the upper female reproductive tract.

\section{Materials and Methods}

Mycoplasma. The strain of $M$. pulmonis used in these studies was kindly supplied by Dr Gail Cassell, University of Alabama in Birmingham, and was originally isolated from naturally infected mice. The mycoplasma were cultured in media consisting of PPLO broth or agar (Difco Laboratories, Detroit, Michigan) supplemented with $20 \%$ horse serum (M.A. Bioproducts, Walkersville, Maryland), 10\% yeast extract (M.A. Bioproducts), $1 \%$ glucose, $0 \cdot 002 \%$ phenol red and $1000 \mathrm{U}$ penicillin $/ \mathrm{ml}$. Cultures in the log phase of growth were centrifuged at $12000 \mathrm{~g}$ for $60 \mathrm{~min}$, washed once in Dulbecco's phosphate-buffered saline (PBS; Gibco, Grand Island, New York) and resuspended in PBS. Aliquots of this suspension were stored at $-20^{\circ} \mathrm{C}$ and contained approximately $10^{9}$ colony forming units (CFU) per $\mathrm{ml}$ after thawing.

Mice. Male (at least 10 weeks old) and female (6-8 weeks old) random-bred, Swiss-white mice were obtained from Taconic Farms (Tarrytown, New York). Preliminary studies showed these animals to be free of naturally occurring mycoplasma infection.

Spermatozoa were released from the epididymis and vas deferens directly into PBS or PBS containing $10^{9} \mathrm{CFU} M$. pulmonis per ml under sterile, pre-warmed $\left(37^{\circ} \mathrm{C}\right)$ mineral oil. In all experiments, pooled sperm suspensions containing approximately $5 \times 10^{7}$ spermatozoa $/ \mathrm{ml}$ from 2 or more mice were used. The spermatozoa were incubated in the PBS or PBS with mycoplasmas for $15 \mathrm{~min}$ at $37^{\circ} \mathrm{C}$ before use. Aliquots of these suspensions were washed and prepared for scanning electron microscopy.

Virgin female mice were induced to superovulate by intraperitoneal injection of 7.5 i.u. PMSG (Gestyl; Organon, West Orange, New Jersey) followed $48-52 \mathrm{~h}$ later by 7.5 i.u. hCG (Sigma Chemical Co., St Louis, Missouri). Females ovulate 12-13 h after hCG administration.

Insemination procedure. For anaesthesia, a stock solution of $25 \mathrm{~g}$ tribromoethanol (Aldrich Chemical Co., Milwaukee, Wisconsin) in $15.4 \mathrm{ml}$ amylene hydrate was prepared. For use, a 40 -fold dilution of the stock in distilled water was made and $0.3-0.4 \mathrm{ml}$ was injected intraperitoneally into each mouse. For intrauterine inseminations, a mid-line incision was made and the cervix and uterine horns were exteriorized. Using a glass micropipette, approximately 15 $\mu \mathrm{l}$ of sperm suspension incubated in PBS alone were injected into one uterine horn. Using the same micropipette, an equal volume of the same pooled sperm suspension that had been preincubated with $M$. pulmonis in PBS was injected into the contralateral uterine horn. A new micropipette was used for each animal and the horns receiving the control and experimental sperm suspensions were randomized so that any variation due to differences in the left and right uterine horns and oviducts could be excluded. Although the actual volumes injected into different animals may have varied slightly, the control and experimental volume that an individual female received was the same. In this way, each animal served as her own control and a paired sample analysis of the data could be performed. Each horn was injected at a point about $4 \mathrm{~mm}$ above the cervix and a 5-0 surgical silk ligature was placed around the uterine horn at the site of injection to prevent backflow of the injected suspension. The wound was closed and the animal allowed to recover.

For bursal inseminations, lateral flank incisions were made and the ovary and oviduct exteriorized. Under a dissecting microscope, approximately $10 \mu \mathrm{l}$ of the appropriate suspension were injected through a fat pad into the ovarian bursa. The spermatozoa were treated as described for intrauterine inseminations and the paired sample design was used. 
At intervals after insemination, the animals were killed by cervical dislocation and the genital tracts exposed. The oviducts were carefully separated from the uteri in situ at a point directly above the utero-tubal junction. Each oviduct was then removed and placed in a separate, dry watchglass. The uteri were removed, minced slightly and placed in $0.2 \mathrm{ml}$ PBS to allow the spermatozoa to swim out. Under a dissecting microscope, each oviduct was flushed with approximately $0.3 \mathrm{ml}$ PBS using a blunted 30 -gauge needle inserted through the infundibulum. The eggs were transferred to $0.1 \%$ hyaluronidase (Sigma Type II) in PBS containing $1 \%$ polyvinylpyrrolidine (Gibco) to remove the cumulus cells if necessary. They were washed once in PBS, fixed, mounted and stained with acetolacmoid as described by Wolf \& Hamada (1979). The eggs from each oviduct were examined by phase-contrast microscopy for evidence of fertilization. An egg was considered fertilized only when a decondensing sperm head or male pronucleus and a sperm tail were visible within the vitellus.

Fluorescence and electron microscopy. For fluorescence microscopy, uterine and oviducal spermatozoa were placed in methanol-acetic acid $(3: 1, \mathrm{v} / \mathrm{v})$ fixative overnight at $4^{\circ} \mathrm{C}$. The spermatozoa were concentrated by centrifugation and samples were placed on coverslips and allowed to dry. The coverslips were then stained with a DNA-binding fluorochrome (No. 33258, Hoechst Pharmaceutical, Somerville, New Jersey) as described previously (Swenson \& O'Leary, 1980) and examined under oil using epi-fluorescence.

For scanning electron microscopy of mycoplasma alone, $M$. pulmonis was grown on glass coverslips in broth. The coverslips were rinsed briefly in PBS before fixation. Spermatozoa that had been incubated with $M$. pulmonis were washed in PBS, fixed and allowed to attach to poly-L-lysine-coated coverslips. Oviducal and uterine flushings were diluted in an ammonium chloride erythrocyte-lysing buffer (Roos \& Loos, 1970) overnight at $4^{\circ} \mathrm{C}$. The spermatozoa were then concentrated on a polycarbonate membrane filter with a pore size of $0.6 \mu \mathrm{m}$ (Nucleopore, Pleasanton, California). All specimens were fixed in $2.5 \%$ glutaraldehyde in $0 \cdot 1$ M-Collidine buffer. The samples were dehydrated in acetone and dried in a Sorvall critical point drying apparatus. Specimens were coated with gold in an Edwards 150 sputter coater and examined at $30 \mathrm{kV}$ in an Etec Autoscan.

Statistical analysis. All means are expressed with the standard error of the mean. The significance of the differences between the control and experimental procedures was determined using the paired-sample $t$ test as described by Zar (1974).

\section{Results}

The strain of $M$. pulmonis used in these studies formed microcolonies when grown on glass coverslips in broth. Individual organisms were highly pleomorphic, forming long, thin filaments, short chains of coccoid cells and large and small spherical forms. Occasionally, filaments with bulb-like tips and branches were seen (Pl. 1, Fig. 1).

When fresh, epididymal mouse spermatozoa were incubated at $37^{\circ} \mathrm{C}$ for $15 \mathrm{~min}$ in the presence of $10^{9} \mathrm{CFU} / \mathrm{ml}$ in PBS, the mycoplasmas were frequently found associated with the convex surface of the sperm head (Pl. 1, Figs 3 and 4) and the tails (Pl. 1, Fig. 2). Between 70 and $80 \%$ of the spermatozoa examined by scanning electron microscopy were associated with mycoplasmas. The adherent mycoplasmas in these preparations were primarily spherical in shape although some filamentous forms were seen.

\section{Uterine insemination}

Fifty mice were inseminated between 8 and $14 \mathrm{~h}$ after hCG administration. Eggs were recovered between 6 and $20 \mathrm{~h}$ after insemination (mean $=11.0 \pm 0.8 \mathrm{~h}$ ) or between 5 and $18 \mathrm{~h}$ (mean $=10.1 \pm 0.6 \mathrm{~h}$ ) after the expected time of ovulation. The oviducal contents of one mouse 
were lost during processing and, in 8 other mice, over $50 \%$ of the eggs recovered from one or both oviducts were abnormal or fragmented. Consequently, most of the analyses were based on the results from 41 animals. The uterine horns and spleens of 10 mice were cultured for mycoplasma. Mycoplasma was recovered from all the horns inseminated with spermatozoa that had been preincubated the $M$. pulmonis. Mycoplasmas were not recovered from the contralateral horns or any of the cultured spleens.

The number of eggs recovered from the oviduct on the mycoplasma-inseminated side did not differ significantly from the number recovered from the contralateral oviduct (Table 1). There were no significant differences in the number of abnormal or fragmented eggs recovered from the oviducts. When the 8 animals who had $>50 \%$ abnormal or fragmented eggs in one or both oviducts were included, the mean values were slightly higher $(19.2 \pm 3.0 \%$ and $15.9 \pm 2.8 \%$ for the mycoplasma-inseminated and contralateral sides respectively) but the differences were still not significant.

Table 1. The effect of preincubation of spermatozoa with $M$. pulmonis on egg recovery, sperm transport and fertilization in the mouse

\begin{tabular}{|c|c|c|c|c|c|}
\hline & \multirow{2}{*}{$\begin{array}{c}\text { Spermatozoa } \\
\text { preincubated } \\
\text { with mycoplasma }\end{array}$} & \multicolumn{2}{|c|}{$\begin{array}{c}\text { Intrauterine } \\
\text { insemination }(N=41)\end{array}$} & \multicolumn{2}{|c|}{$\begin{array}{c}\text { Ovarian bursa } \\
\text { insemination }(\mathrm{N}=25)\end{array}$} \\
\hline & & Mean & $\begin{array}{c}\text { Mean } \\
\text { difference }\end{array}$ & Mean & $\begin{array}{c}\text { Mean } \\
\text { difference }\end{array}$ \\
\hline No. of eggs recovered & + & $\begin{array}{l}10.7 \pm 1.0 \\
10.7 \pm 1.0\end{array}$ & $0.0 \pm 0.7$ & $\begin{array}{l}10.4 \pm 1.3 \\
10.1 \pm 1.3\end{array}$ & $0 \cdot 3 \pm 1.4$ \\
\hline$\%$ Abnormal and fragmented & $\begin{array}{l}+ \\
-\end{array}$ & $\begin{array}{l}14 \cdot 1 \pm 2 \cdot 4 \\
10 \cdot 6 \pm 2 \cdot 0\end{array}$ & $3 \cdot 5 \pm 3 \cdot 1$ & $\begin{array}{l}15 \cdot 8 \pm 3.4 \\
15 \cdot 5 \pm 2.7\end{array}$ & $0.7 \pm 3.9$ \\
\hline Sperm : egg ratio & $\begin{array}{l}+ \\
-\end{array}$ & $\begin{array}{l}0.54 \pm 0.07 \\
0.76 \pm 0.08\end{array}$ & $0.22 \pm 0.09^{*}$ & $\begin{array}{l}1.34 \pm 0.26 \\
1.13 \pm 0.15\end{array}$ & $0.23 \pm 0.23$ \\
\hline$\%$ Normal eggs fertilized & $\begin{array}{l}+ \\
-\end{array}$ & $\begin{array}{l}44.7 \pm 5.8 \\
61.4 \pm 6.0\end{array}$ & $16 \cdot 7 \pm 5 \cdot 5 \dagger$ & $\begin{array}{l}76 \cdot 1 \pm 5 \cdot 5 \\
75 \cdot 2 \pm 5 \cdot 2\end{array}$ & $1.9 \pm 6.8$ \\
\hline
\end{tabular}

* Significant by the paired-sample $t$ test $(0.02<P<0.01)$.

$\dagger$ Significant by the paired-sample $t$ test $(0.005<P<0.002)$.

A significant difference was found in the number of spermatozoa associated with the eggs (spermatozoa within or attached to the egg) and for the number of normal, fertilized eggs recovered (Table 1). The sperm: egg ratios and the percentage of normal eggs fertilized increased with time after insemination (Text-fig. 1). Except for the small group of animals examined at the earliest time after insemination, there were more spermatozoa associated with the eggs from the control side at each time point than those from the side inseminated with mycoplasma-treated

\section{PLATE 1}

Fig. 1. Scanning electron micrograph of $M$. pulmonis organisms and microcolonies grown on a glass coverslip in broth. $\times 7790$.

Figs 2-4. Scanning electron micrographs of spermatozoa after incubation at $37^{\circ} \mathrm{C}$ for $15 \mathrm{~min}$ with $10^{9} \mathrm{CFU} M$. pulmonis/ml in PBS. Figs 2 and 3, $\times 6650$; Fig. 4, $\times 7300$

Fig. 5. Uterine contents of mice 6-8 h after intrauterine insemination with spermatozoa that had been preincubated with $M$. pulmonis. Mycoplasma-like forms can be seen adherent to a sperm head. $\times 19500$.

Fig. 6. Oviducal contents of mice 6-8 h after intrauterine insemination with spermatozoa that had been preincubated with $M$. pulmonis. Mycoplasma-like forms are seen adherent to the head of a spermatozoon. $\times 7700$. 
PLATE 1
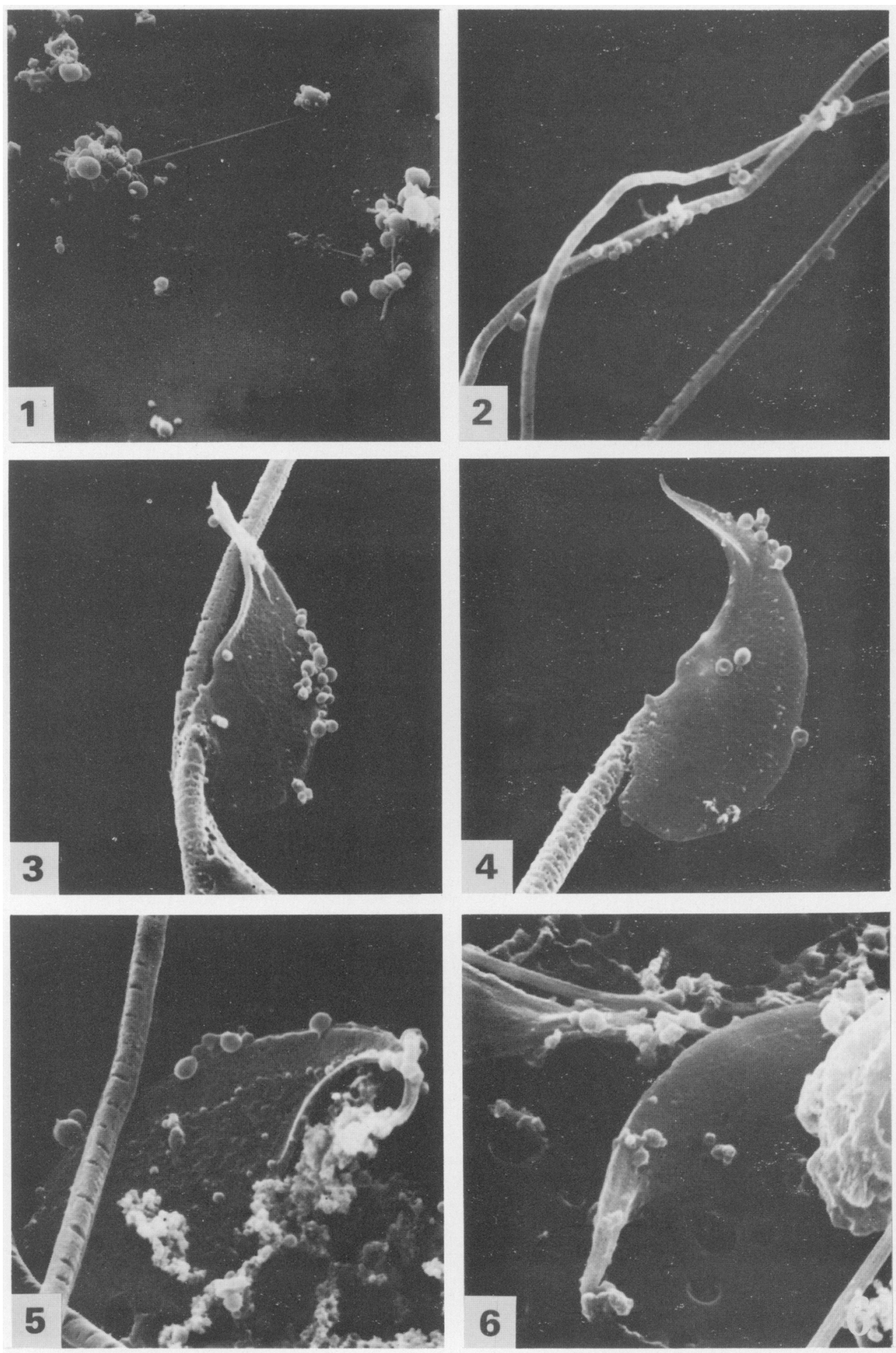

$1+a \cdot m g) \cdot 260)$ 

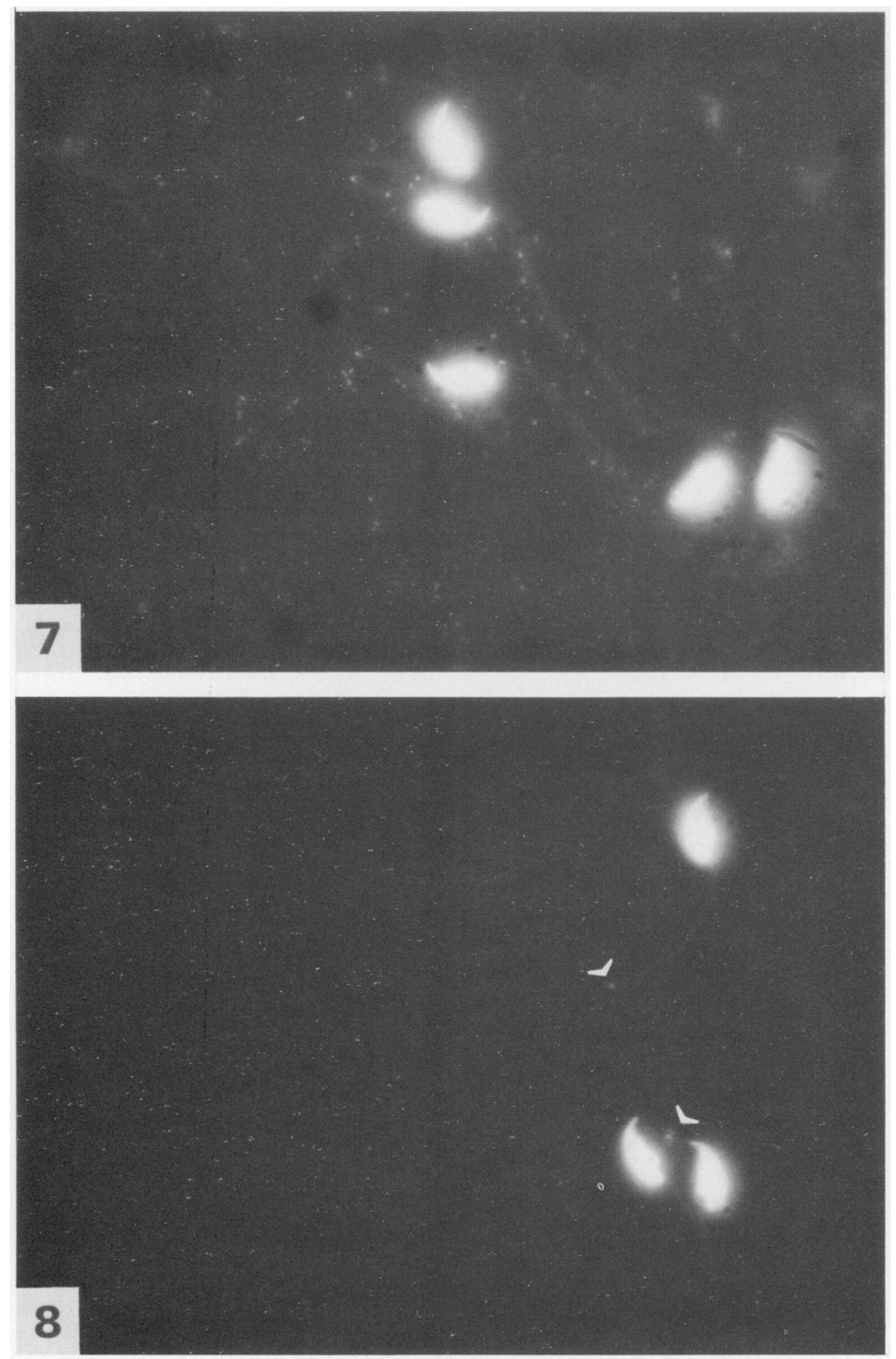

Fig. 7. Hoechst-stained preparation of mouse uterine contents $6-8 \mathrm{~h}$ after intrauterine insemination with spermatozoa preincubated with $M$. pulmonis. The nuclei of spermatozoa appear brightly fluorescent. Many discrete DNA-containing particles consistent with myco plasma are seen attached to and surrounding the spermatozoa. $\times 1425$.

Fig. 8. Hoechst-stained preparation of mouse oviducal contents $6-8 \mathrm{~h}$ after intrauterine insemination with spermatozoa preincubated with $M$. pulmonis. Several mycoplasma-like particles are visible (arrows), but there are very few compared with Fig. 7. $\times 1425$. 


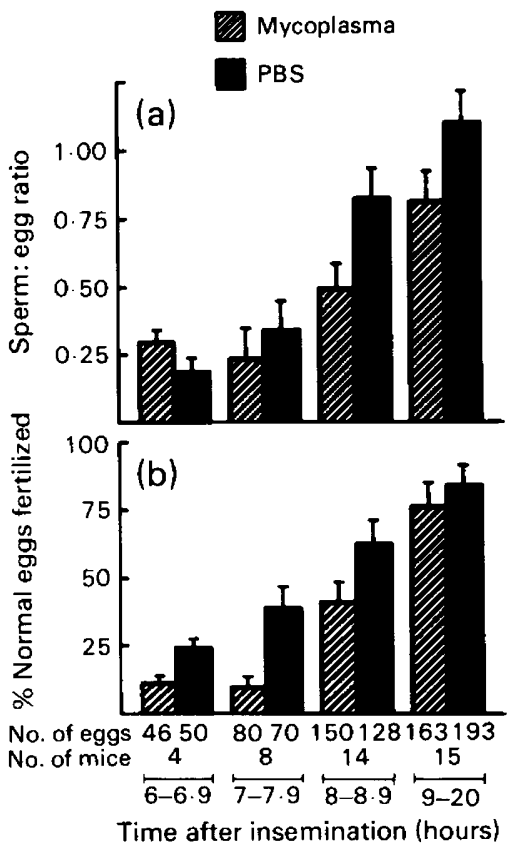

Text-fig. 1. The mean sperm:egg ratio (a) and percentage of normal eggs fertilized (b) at intervals after intrauterine insemination with spermatozoa that had been preincubated with $M$. pulmonis and spermatozoa preincubated in PBS alone. Bars above the columns represent the s.e.m.

sperm. At each interval, a greater percentage of eggs from the control oviducts were fertilized than from the mycoplasma-inseminated side.

\section{Sperm motility}

Seven female mice were inseminated 11-12 h after hCG; one uterine horn received spermatozoa that had been preincubated with mycoplasmas and the other received control spermatozoa. At intervals, the animals were killed and uterine spermatozoa were collected. The spermatozoa were diluted in a drop of PBS such that the concentration was approximately $5 \times$ $10^{6} / \mathrm{ml}$ and the motility of 100 spermatozoa from each uterine horn was evaluated using phase-contrast microscopy. Each spermatozoon was given a motility rating of 1 (no movement), 2 (the tail showed twitching or waving movements) or 3 (the spermatozoa showed forward progression). A mean motility score was then calculated for each sample. The spermatozoa retained good motility up to $4 \mathrm{~h}$ after insemination. Thereafter, the motility scores appeared to decline although some motile spermatozoa were found as late as $8 \mathrm{~h}$ after insemination. There were no significant differences in the motility scores of mycoplasma-treated and untreated uterine spermatozoa.

Association of spermatozoa and mycoplasma. Uterine and oviducal flushings from 5 animals $6-8 \mathrm{~h}$ after intrauterine insemination were examined by scanning electron microscopy. Although cellular debris and blood cells tended to obscure many of the spermatozoa recovered in this manner, mycoplasmas were clearly seen associated with the heads (Pl. 1, Fig. 5) and tails of uterine spermatozoa. In several instances, small, pleomorphic particles consistent with mycoplasmas were found adherent to spermatozoa from the oviducts on the sides inseminated with mycoplasma-treated spermatozoa (Pl. 1, Fig. 6). 
Uterine and oviducal flushings were obtained from 7 additional females after intrauterine insemination. The flushings were concentrated by centrifugation and stained with the Hoechst stain. In addition to spermatozoa and cellular debris, the uterine flushings contained many small, DNA-containing particles consistent with mycoplasma (Pl. 2, Fig 7). Of 200 uterine spermatozoa examined, $73 \%$ appeared to have mycoplasmas adherent to their heads or tails. In contrast, the oviducal flushings contained very few particles consistent with mycoplasma (Pl. 2, Fig 8); only $14.4 \%$ of 216 oviducal spermatozoa examined had mycoplasmas adherent to them.

Insemination into the ovarian bursa. Insemination was performed after the majority of the eggs were ovulated $(14.5 \pm 0.2 \mathrm{~h}$ after $\mathrm{hCG}$; range $=13-16 \mathrm{~h})$ so that manipulations of the bursa would not interfere with ovum pick-up. The animals were killed for egg recovery between 5.5 and $7.2 \mathrm{~h}$ after insemination $(6.5 \pm 0.1 \mathrm{~h})$. Of the 30 mice inseminated, 5 had $>50 \%$ abnormal or fragmented eggs in one or both oviducts and were therefore excluded from most analyses. There were no significant differences between the sides inseminated with spermatozoa alone and those inseminated with mycoplasma-treated spermatozoa (Table 1).

\section{Discussion}

Preincubation of fresh, epididymal mouse spermatozoa with $M$. pulmonis resulted in a significant decrease in the fertilization of mouse eggs in vivo after intrauterine insemination. The finding that the number of spermatozoa associated with eggs was also reduced after mycoplasma treatment suggests that these organisms may interfere with the transport of spermatozoa to the site of fertilization and/or with the interaction of spermatozoa with the egg vestments.

Although genital mycoplasma colonization is not normally found in mice, the strain of $M$. pulmonis used in these studies was shown by fluorescence and scanning electron microscopy to adhere to mouse spermatozoa after a short in-vitro incubation period. Spermatozoa that had been in the mouse uterus for $6-8 \mathrm{~h}$ were still found to have adherent mycoplasmas. It has been postulated that several sites in the female reproductive tract represent 'barriers' through which only a small proportion of 'select' spermatozoa may pass. These barriers may be at the cervix (Morton \& Glover, 1974), the utero-tubal junction (Krzanowska, 1974; de Boer, van der Hoeven \& Chardon, 1976), the isthmus or isthmus-ampullary junction (Braden, 1953; Nicol \& McLaren, 1974) and/or the cumulus cell mass (Overstreet \& Bedford, 1974). Using the Hoechst stain to detect mycoplasmas, it was found that the percentage of spermatozoa with adherent mycoplasmas was lower in the oviduct than in the uterus. Although this procedure may underestimate the actual number of mycoplasmas present (as some organisms may be obscured by the bright fluorescence of the sperm nucleus), the ratio suggests that the passage of mycoplasma-infected spermatozoa into the oviduct is less effective than that of normal spermatozoa.

Chow, Carlsen \& Sorrell (1980) injected a suspension of Escherichia coli into the uteri of oestrous mice and found that the mean bacterial counts in the uterine horn were significantly higher than in the contiguous oviduct, suggesting that the uterotubal junction acted as a barrier to bacterial passage into the oviduct. The results presented here suggest that the uterotubal junction is also capable of excluding the passage of $M$. pulmonis, as very few free mycoplasmas were recovered in oviducal flushings compared to uterine flushings. The uterotubal junction is not an absolute barrier however, since some spermatozoa recovered from the oviduct were found to have adherent mycoplasmas by both fluorescence and scanning electron microscopy. Spermatozoa may facilitate the passage of these organisms into the upper female genital tract.

The presence of mycoplasmas in sperm suspensions inseminated directly into the ovarian bursa did not reduce the fertilization rate. Although the majority of spermatozoa in these suspensions had adherent mycoplasmas which may affect their function or interfere mechanically with binding and fusion, apparently there were still enough unaffected, normal 
spermatozoa in the immediate vicinity of the eggs to fertilize as many ova as in control preparations.

Fraser \& Taylor-Robinson (1977), using cleavage to the 2-cell stage as their criterion for fertilization, found a reduction in the fertilization rate in vitro when spermatozoa were preincubated with mycoplasmas. There was also a reduction in development to the blastocyst stage. They suggested that some metabolic product produced by viable $M$. pulmonis was responsible for the effect seen. It is possible that the metabolic activity of mycoplasma is not as deleterious in vivo or that its effect is not seen until the time of cleavage. Several Mycoplasma species have been reported to cause mitotic inhibition and chromosomal damage in cell cultures (Nichols, 1978). These effects would probably not have been evident in this study, which considered only the initial stages of fertilization. Alternatively, the pathogenicity of the strains of M. pulmonis used in this study and that of Fraser \& Taylor-Robinson (1977) may have differed.

Mycoplasmas have been found in the semen of a variety of mammals including pigs (Stipkovits, Rashwan, Takacs \& Lapis, 1978), sheep (Jones \& Rae, 1979), bulls (Jurmanova \& Sterbova, 1977), stallions (Kirchoff, Naglie \& Heitmann, 1979), chimpanzees (Swenson \& O'Leary, 1977) and men (O'Leary \& Frick, 1975). In bulls (Stalheim \& Gallagher, 1977) and men (Gnarpe \& Friberg, 1973b; Fowlkes, Dooher \& O'Leary, 1975) genital mycoplasmas have been shown to adhere to spermatozoa and colonies of several species of mycoplasma on agar will adsorb spermatozoa (Taylor-Robinson \& Manchee, 1967). The natural presence of mycoplasmas in the semen has been associated with impaired sperm motility in men (Fowlkes, MacLeod \& O'Leary, 1975; Swenson, Toth \& O'Leary, 1979) and bulls (Jurmanova \& Sterbova, 1977). In the studies presented here, incubation of epididymal spermatozoa with $M$. pulmonis in vitro before insemination did not appear to affect the motility of uterine spermatozoa. It is possible that subtle alterations in motility characteristics were not detected in this study, or that mycoplasmas must be present in the testis or epididymis to affect sperm motility.

In conclusion, this study has shown that $M$. pulmonis adsorbs to the surface of murine spermatozoa and that the presence of mycoplasma in sperm suspensions reduces the fertilization rate in vivo of mouse eggs after intrauterine insemination.

I thank Dr Patricia M. Saling for her advice on some of the surgical procedures used and Dr David M. Phillips, in whose laboratory this work was done, for his help, advice and critical review of the manuscript. This work was supported by National Research Service Award No. 1 F32 HD06132-01 and National Institutes of Health grants Nos. HD-15113-01 and HD-13541.

\section{References}

Braden, A.W.H. (1953) Distribution of sperms in the genital tract of the female rabbit after coitus. Aust. $J$. biol. Sci. 6, 693-705.

Chow, A.W., Carlson, C. \& Sorrell, T.C. (1980) Bacterial clearance in the murine uterus and oviduct. Am.J. Obstet. Gynec. 138, 1003-1005.

Cole, B.C., Ward, J.R. \& Golightly-Rowland, L. (1973) Factors influencing the susceptibility of mice to Mycoplasma arthriditis. Infect. Immun. 7, 218-225.

de Boer, P., van der Hoeven, F.A. \& Chardon, J.A.P. (1976) The production, morphology, karyotypes and transport of spermatozoa from tertiary trisomic mice and the consequences for egg fertilization. J. Reprod. Fert. 48, 249-256.

Fowlkes, D.M., Dooher, G.B. \& O'Leary, W.M. (1975)
Evidence by scanning electron microscopy for an association between spermatozoa and T-mycoplasmas in men of infertile marriage. Fert. Steril. 26, 1202-1211.

Fowlkes, D.M., MacLeod, J. \& O'Leary, W.M. (1975) T-mycoplasmas and human infertility: correlation of infection with altered semen parameters. Fert. Steril. 26, 1212-1218.

Fraser, L.R. \& Taylor-Robinson, D. (1977) The effect of Mycoplasma pulmonis on fertilization and preimplantation development in vitro of mouse eggs. Fert. Steril. 28, 488-498.

Gabridge, M.G. \& Cohen, L.J. (1976) Development of an animal model for mycoplasma related reproductive failure. Lab. Anim. Sci. 26, 206-210. 
Gnarpe, H. \& Friberg, J. (1972) Mycoplasma and human reproductive failure. I. The occurrence of different mycoplasmas in couples with reproductive failure. Am.J. Obstet. Gynec. 114, 727-731.

Gnarpe, H. \& Friberg, J. (1973a) T-mycoplasmas as a possible cause of reproductive failure. Nature, Lond. 242, 120-121.

Gnarpe, H. \& Friberg, J. (1973b) T-mycoplasmas on spermatozoa and infertility. Nature, Lond. 245, 297.

Henry-Suchet, J. \& Loffredo, V. (1980) Chlamydia and mycoplasma genital infection in salpingitis and tubal sterility. Lancet 1, 539.

Jones, G.E. \& Rae, A.G. (1979) Ureaplasmas in sheep. Vet. Rec. 104, 466.

Jurmanova, K. \& Sterbova, J. (1977) Correlation between impaired spermatozoal motility and mycoplasma findings in bull semen. Vet. Rec. 100, $157-158$.

Kirchoff, H., Naglie, T. \& Heitmann, J. (1979) Isolation of Acholeplasma laidlawii and Mycoplasma equigenitalium from stallion semen. Vet Microbiol. 4, $177-179$.

Koren, Z. \& Spigland, I. (1978) Irrigation technique for detection of Mycoplasma intrauterine infection in infertile patients. Obstet. Gynecol., N.Y. 52, 588-590.

Krzanowska, H. (1974) The passage of abnormal spermatozoa through the uterotubal junction of the mouse. J. Reprod. Fert. 38, 81-90.

Mardh, P.-A. \& Westrom, L. (1970) Tubal and cervical cultures in acute salpingitis with special reference to Mycoplasma hominis and T-strain mycoplasmas. $B r$. J. Vener. Dis. 46, 179-186.

Morton, D.B. \& Glover, T.D. (1974) Sperm transport in the female rabbit: the role of the cervix. $J$. Reprod. Fert. 38, 131-138.

Naot, Y., Sharf, M. \& Klein, A. (1978) Mycoplasma infection in pregnant rats: low viability of foetuses and newborn offspring. J. Med. Microbiol. 11, 261-267.

Nichols, W.W. (1978) Genetic effects of mycoplasma. In Mycoplasma Infection of Cell Cultures, pp. 151-157. Eds G. J. McGarrity, D. G. Murphy \& W. W. Nichols. Plenum Press, New York.

Nicol, A. \& McLaren, A. (1974) An effect of the female genotype on sperm transport in mice. J. Reprod. Fert. 39, 421-424.
O'Leary, W.M. \& Frick, J. (1975) The correlation of human male infertility with the presence of mycoplasma T-strains. Andrologia 7, 309-316.

Overstreet, J.W. \& Bedford, J.M. (1974) Importance of sperm capacitation for gamete contact in the rabbit. J. Reprod. Fert. 39, 393-398.

Roos, D. \& Loos, J.A. (1970) Changes in the carbohydrate metabolism of the mitogenically stimulated human peripheral lymphocytes. I. Stimulation by phytohemagglutinin. Biochim. Biophys. Acta. 222, 565-571.

Stalheim, O.H.V. \& Gallagher, J.E. (1977) Adherence and adsorption of mycoplasmas to spermatozoa. Ann. Meeting. Am. Soc. Microbiol. 77, 132, Abstr.

Stipkovits, L., Rashwan, A., Takacs, J. \& Lapis, K. (1978) Occurrence of ureaplasmas in swine semen. Zentbl. Vet Med. B 25, 605-608.

Stray-Pedersen, B., Eng, J. \& Reikvam, T.M. (1978) Uterine $\mathrm{T}$-mycoplasma colonization in reproductive failure. Am.J. Obstet. Gynec. 130, 307-311.

Swenson, C.E. \& O'Leary, W.M. (1977) Genital Ureaplasmas in non-human primates. J. Med. Primatol. 6, 344-348.

Swenson, C.E. \& O'Leary, W.M. (1980) Examination of human semen infected with Ureaplasma urealyticum by fluorescence microscopy. Arch. Androl. 5, 373377.

Swenson, C.E., Toth, A. \& O'Leary, W.M. (1979) Ureaplasma urealyticum and infertility: the effect of antibiotic therapy on semen quality. Fert. Steril. 31, 660-665.

Taylor-Robinson, D. \& Manchee, R.J. (1967) Spermadsorption and spermagglutination by mycoplasmas. Nature, Lond. 215, 484-487.

Taylor-Robinson, D., Rassner, C., Furr, P.M., Humber, D.P. \& Barnes, R.D. (1975) Fetal wastage as a consequence of Mycoplasma pulmonis infection in mice. J. Reprod. Fert. 42, 483-490.

Wolf, D.P. \& Hamada, M. (1979) Sperm binding to the mouse egg plasmalemma. Biol. Reprod. 21, 205-211.

Zar, J.H. (1974) Biostatistical Analysis. Prentice Hall, New Jersey. 